\title{
KERAGAMAN JENIS KADAL SUB-ORDO SAURIA (FAMILI SCINCIDAE) DI HUTAN TAMAN WISATA ALAM GUNUNG MEJA
}

\section{(Diversity Rate of Lizard Sub-Ordo Sauria [Famili Scincidae] in Gunung Meja Natural Tourism Forest)}

\author{
Muhammad Agus Sukardi ${ }^{1}$ dan Anton Silas Sinery ${ }^{1 凶}$ \\ Jurusan Kehutanan, Fakultas Kehutanan Universitas Papua Manokwari, Papua Barat, \\ 98314. Tlp/Fax: +62986211065. \\ ${ }^{\square}$ Penulis Korespondensi: Email: sineryanton@yahoo.co.id \\ Diterima: 20 Jan 2018| Disetujui: 11 Feb 2018
}

\begin{abstract}
Abstrak
Tujuan dari penelitian ini adalah untuk mengetahui jenis-jenis kadal dan keragamannya pada Hutan Taman Wisata Alam Gunung Meja. Studi ini menggunakan teknik observasi dan teknik pengambilan data secara langsung melalui penjelajahan dengan parameter utama meliputi jenis, jumlah individu kadal sedangkan variabel pendukung meliputi kondisi umum lokasi penelitian. Hasil penelitian ini menunjukkan bahwa terdapat six jenis kadal yakni: Sphenomophus sp., Sphenomorphus variegatus (Peters, 1867), Carlia fusca (Dumeril \&Bibron, 1836), Laprolepis smaragdina (Lesson, 1830) Emoia sp dan Emoia caeruleocouda (Des, 1892) dengan jumlah total individu 133. Tingkat keanekaragaman jenis kadal sebesar 1,76 (kriteria sedang) yang menunjukkan kemantapan populasi kadal yang cukup baik dan tingkat kemerataan jenis tinggi $(0,98)$ yang menunjukkan adanya distribusi individu yang merata. Jenis-jenis kadal tersebut ada yang bersifat arboreal, teresterial dan dibawah tanah dan umumnya beradaptasi pada tumpukan serasah, pohonpohon tumbang dan daerah terbuka serta memiliki jenis pakan berupa jenis serangga dan beberapa jenis organism berukura kecil.
\end{abstract}

Kata kunci: Herpetofauna, keragaman jenis kadal, hutan tropis, TWA Gunung Meja.

\begin{abstract}
The aim of this study was to acknowledge types of lizard and its density rate in Gunung Meja natural tourism forest. The study used observation technic and data were taken directly through on the move field observation in order to collect data such as lizard species, number as well as the overall overview of the study area. The result noticed that there were six species of lizards found namely: Sphenomophus sp., Sphenomorphus variegatus (Peters, 1867), Carlia fusca (Dumeril \&Bibron, 1836), Laprolepis smaragdina (Lesson, 1830) Emoia sp. and Emoia caeruleocouda (Des, 1892) with the total number of 133 individu. The diversity rate of lizard species was 1.76 (moderate criteria) whuch showed the stability population and a slightly higher of evenness rate (0.98) of the lizard species in the area. These lizards' species were classified into arboreal, terrestrial, and soil-based lizard habitat which was dominated on the forest litter as well as open area. These lizards were feeded by small insects and other small forest organisms.

Keywords: Herpetofauna, lizard species diversity, tropical forest, Gunung Meja natural tourism forest.
\end{abstract}

9

@ Asosiasi Peneliti Biodiversitas Papuasia - Fakultas Kehutanan UNIPA 


\section{PENDAHULUAN}

Herpetofauna (amfibi dan reptil) berasal dari kata herpeton yang berarti binatang melata. Pada awalnya sebelum ilmu taksonomi berkembang maju, amfibi dan reptil dimasukkan kedalam satu kelompok hewan karena dianggap samasama melata. Namun seiring dengan berkembangnya ilmu pengetahuan dibidang ilmu pengetahuan khususnya ilmu tentang biologi akhirnya dipisahkan menjadi dua kelompok. Kedua kelompok ini dimasukkan ke dalam bidang ilmu herpetologi karena mempunyai cara hidup yang serupa, yaitu sama-sama satwa vertebrata ektoternal (membutuhkan suhu panas eksternal). Amfibi maupun reptil dapat dijumpai mulai dari dataran rendah sampai pada dataran tinggi. Amfibi tidak dijumpai dilaut sedangkan reptil dapat dijumpai pada lautan (Mack et al. 2000).

Keberadaan herpetofauna (reptil dan amfibi) semakin hari semakin terancam kehidupannya dan bahkan sebagian telah mengalami kepunahan terhadap jenisnya. Perhatian dan penanganan terhadap herpetofauna khususnya kadal sampai sekarang masih terabaikan, minat serta ketertarikan untuk melakukan penelitian tentang reptil dan amfibi sangat kurang, sehingga masih banyak spesies herpetofauna yang belum teridentifikasi dan bahkan belum diketahui jenisnya lalu akhirnya mengalami kepunahan (Muller 2005).

Saat ini reptil dan amfibi merupakan satwa buruan yang sering di lakukan oleh masyarakat untuk di manfaatkan dagingnya maupun sebagian dari tubuhnya. Ular, buaya, biawak, kadal, penyu dan kura-kura mempunyai nilai jual yang tinggi, selain dagingnya dapat dikonsumsi oleh kalangan tertentu, kulit dan sebagian fisiknya pun dapat dibuat pernak-pernik dan hiasan yang sangat berkualitas.

Berbagai laporan penelitian diperkirakan ada sekitar 54 jenis mamalia (43\% dari jumlah mamalia terdapat di Papua), 41 jenis amfibi dan reptilian 171 jenis aves (burung). Beberapa jenis yang telah disebutkan telah ditemukan jenisjenis baru, berbagai ilmu pengetahuan telah dicatat dalam kegiatan peneliti mahasiswa Universitas Cenderawasih (UNCEN, Jayapura), UNIPA Manokwari (UNIPA) dan Conservation International Indonesia (Conservation Internasional 2003). Menurut Krey (2002) dalam Werimon (2006), dari penelitian yang dilakukan telah di temukan 41 jenis herpetofauna yang terdiri dari 16 jenis katak, 16 jenis kadal, 7 jenis ular 1 jenis kura-kura dan 1 jenis buaya di Pulau Waigeo Kabupaten Raja Ampat. Jumlah ini mungkin akan bertambah jika dilakukan penelitian lebih lanjut (Werimon 2006). Penelitian ini bertujuan untuk mengetahui jenis-jenis kadal Ordo Sauria dalam Famili Scincidae di hutan alam Taman Wisata Alam Gunung Meja yang di lihat dari struktur morfologi dan warna tubuhnya.

\section{METODE PENELITIAN}

\section{Gambaran Umum}

Penelitian ini berlangsung selama 2 bulan dari bulan Maret s/d Mei tahun 2014 yang berlokasi pada kawasan Taman Wisata Alam Gunung Meja Kabupaten Manokwari. Metode yang digunakan dalam penelitan ini adalah metode deskriptif dengan teknik observasi. Teknik observasi merupakan teknik pengambilan data secara langsung 
untuk memperoleh data secara langsung melalui penjelajahan. Variabel dalam penelitian ini terdiri atas veriabel utama dan variabel pendukung. Variabel utama meliputi jenis, jumlah individu kadal sedangkan variabel pendukung meliputi kondisi umum lokasi penelitian.

\section{Prosedur penelitian}

Pelaksanaan penelitian dilakukan dengan teknik observasi lapangan melalui langkah-langkah sebagai berikut:

\section{Penentuan lokasi pengamatan}

Sebelum dilakukan penelitian terlebih dahulu dilakukan penentuan lokasi penelitian yaitu menarik $50 \mathrm{~m}$ dari jalan tengah yang mencakup areal sebelah barat (hutan sekunder) dan sebelah timur dari jalan koridor tengah kawasan dari arah selatan menuju utara (hutan primer) TWA Gunung Meja.

2. Penentuan jalur pengamatan secara jelajah.

Setelah penentuan lokasi pengamatan selanjutnya dilakukan penentuan dan pembuatan jalur pengamatan (transek) berukuran panjang $500 \mathrm{~m}$ (masingmasing lokasi) dengan lebar sesuai jarak pandang minimal $20 \mathrm{~m}$ (10 m kanan-kiri transek). Untuk pembuatan jalur pengamatan diupayakan tidak dilakukan pembersihan jalur /penebatasan/penebangan vegetasi. Pembuatan jalur pada kedua lokasi pengamatan berupa jalur tunggal yang membentang dari arah selatan menuju utara kawasan TWA Gunung Meja pada posisi $360^{\circ}$.

3. Identifikasi dan pengumpulan data.

Pendataan dilakukan secara langsung terhadap jenis dan individu kadal yang dijumpai di sepanjang transek. Proses identifikasi dilakukan secara langsung dengan melihat karakter morfologi kadal yang dijumpai selanjutnya dibandingkan dengan buku lapangan (pengenalan jenis reptil).

Untuk memudahkan proses identifikasi pada tahap awal dilakukan penangkapan secara langsung terhadap individu kadal berdasarkan masingmasing jenis sesuai karakter morfologi dengan menggunakan bius. Individu yang telah diketahui jenisnya langsung dilakukan pendataan terhadap individu, sedangkan untuk individu yang belum diketahui jenis diupayakan untuk penangkapan individu.

\section{Analisis data}

Data hasil pengamatan yang terdiri atas data jenis dan individu kadal selanjutnya dianalisis secara tabulasi sedangkan data kondisi habitat dan jenis pakan akan dideskripsikan. Untuk mengetahui variasi jenis sebagai gambaran kemantapan populasi, maka dilakukan analisis keanekaragaman jenis dengan menggunakan persamaan menurut Shannon-Weiner (1949); Odum (1993) dalam Sinery dkk. (2012):

$$
\mathrm{H}=-\sum \frac{\mathrm{ni}}{\mathrm{N}} \mathrm{XLn} \frac{\mathrm{ni}}{\mathrm{N}}
$$

Keterangan:

$\mathrm{H}^{`}=$ Indeks keragaman Shannon Weiner

ni $=$ Jumlah individu jenis ke $\mathrm{i}$

$\mathrm{N}=$ Jumlah individu seluruh jenis.

Untuk mengetahui distribusi individu menurut jenis yang menggambarkan kemerataan jenis, dilakukan analisis dengan menggunakan Indeks Kemerataan Jenis dengan menggunakan persamaan menurut Magurran (1988) dalam Sinery $d k k(2012)$

$$
\mathrm{E}=\frac{\mathrm{H}}{\operatorname{Ln} S}
$$


Keterangan:

$\mathrm{E}^{`}=$ Indeks kemerataan jenis

$\mathrm{H}^{`}=$ Indeks keragaman jenis Shannon Weiner

$\mathrm{S}$ = Jumlah jenis yang ditemukan

\section{HASIL DAN PEMBAHASAN}

\section{Jenis Kadal yang di jumpai}

Berdasarkan hasil pengamatan selama dua bulan dengan frekuensi 5 kali pengamatan diketahui bahwa di kawasan Taman Wisata Gunung Meja diidentifikasi 6 jenis kadal yang tergolong dalam Sub Ordo Sauria dari familiScincidae. Berikut dideskripsikan karakter morfologi dan kondisi habitat serta jenis pakan keenam jenis kadal yang diidentifikasi.

\section{Sphenomorphus sp.}

Panjang tubuh kadal Sphenomorphus sp. mulai dari ujung kepala sampai ekor (SVL) $12 \mathrm{~cm}$, panjang ekor 7,5 cm, panjang kepala dari ujung kepala sampai leher $2 \mathrm{~cm}$, lebar kepala $1 \mathrm{~cm}$, bentuk kepala lancip/meruncing, letak pupil horizontal dan bentuk pupil bulat oval, mempunyai kaki empat setiap kakinya mempunyai ruas jari-jari,kaki depan mempunyai jari empat dan di kaki belakang mempunyai ruas jari lima, warna tubuh hitam kecoklatan dengan empat garis berwarna kuning keemasan pada bagian tubuh mulai dari samping mata sampai pangkal ekor serta tekstur tubuhlicin dan mengkilap.

Kadal jenis ini dapat dijumpai dilantai hutan sekunder, hutan tanaman yang lembab dengan suhu $\pm 26-30{ }^{\circ} \mathrm{C}$ dan pada ketinggian 5-10 mdpl. Daerah semaksemak dan bebatuan. Kadal ini dapat di jumpai pada pagi hari sekitar pukul 08.00 sampai pada pukul 11.00 siang, kadal jenis ini menghabiskan waktunya di darat (teresterial) dengan kelembaban yang cukup sesuai kebutuhan suhu tubuhnya.Pada keadaan tertentu kadal jenis Sphenomorphus sp.biasanya terdapat pada lubang-lubang kayu rebah, serasa dan tumpukan batu. Pada saat hujan kadal jenis ini biasanya bersembunyi di balik batu atau serasa. Jenis makan/pakankadal jenis ini adalah serangga, jentik-jentik nyamuk, nyamuk dan mikroorganisme lain yang ukurannya lebih kecil dari ukuran tubuhnya (Kurniati 2001).

\section{Carlia fusca Dumeril \&Bibron} (1836).

Panjang tubuh dari ujung kepala (mulut) sampai ujung ekor(SVL) $15 \mathrm{~cm}$, panjang ekor $9 \mathrm{~cm}$, panjang kepala sampai leher $2 \mathrm{~cm}$, lebar kepala $1 \mathrm{~cm}$, letak mata horizontal, bentuk mata oval, mempunyai kaki empat dengan masing-masing kaki mempunyai ruas jari, tungkai kaki depan mempunyai empat ruas jari dan tungkai kaki belakang mempunyai lima jari. Bagian ekor mempunyai sisik sedikit kasar dengan sisik yang kecil dan berwarna tubuh coklat menyeluruh sedikit mengkilap serta tekstur tubuh halus.

Kadal jenis ini secara umum mudah ditemukan pada lantai hutan sekunder yang bervegetasi rendah, semak-semak, bekas kebun, kadal jenis ini biasa juga disebut kadal tanah (teresterial).Dibalik ranting atau daun yang kering, daerah terbuka seperti padang rumput dan daerah tempat pemukiman.

Jenis pakan kadal ini meliputi serangga,kupu-kupu, cacing, jentik-jentik nyamuk dan mikro organisme lain yang tubuhnya lebih kecil dari tubuhnya (Kurniati 2001). 

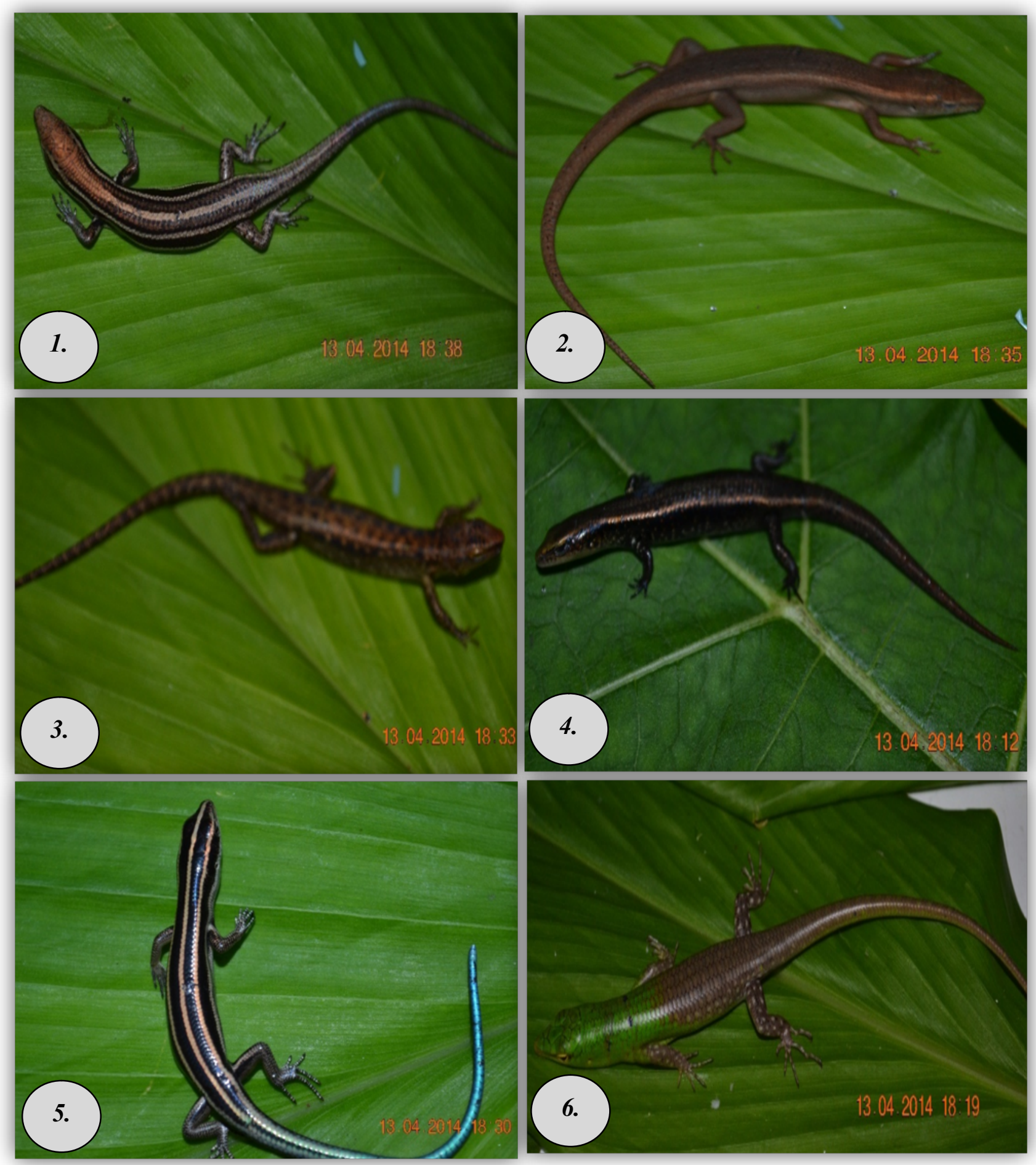

Gambar 1. 1). Jenis Sphenomorphus sp., 2). Carlia fusca Dumeril \&Bibron (1836), 3). Sphenomorphus variegatus(Peters, 1867), 4). Emoia sp., 5). Emoia caeruleocouda (Des, 1892), 6). Leprolepis smaragdina (Lesson, 1830).

@ Asosiasi Peneliti Biodiversitas Papuasia - Fakultas Kehutanan UNIPA 
3. Sphenomorphus variegatus (Peters, 1867).

Panjang tubuh mulai dari monconng sampai ekor (SVL) $11 \mathrm{~cm}$, panjang ekor mulai dari tibia sampai ujung ekor $8 \mathrm{~cm}$, panjang kepala 1,3 cm, lebar kepala 1 $\mathrm{mm}$, letak mata horizontal, bentuk mata oval, mempunyai ruas kaki empat dan setiap kaki mempunyai ruas jari, tungkai kaki depan mempunyai empat ruas jari dan tungkai kaki belakang mempunyai ruas jari lima. Warna tubuh coklat dengan bintik-bintik hitam pada seluruh tubuh dan ekor terdapat garis-garis lingkaran berwarna hitam.

Habitat kadal jenis Sphenomophus variegatus (Hamidy dan Mulyadi 2007) terdapat pada lantai hutan primer maupun sekunder yang mempunyai kelembaban yang cukup tinggi yakni suhu rata-rata \pm $26-28{ }^{\circ} \mathrm{C}$ dan dapat ditemukan pada ketinggian sekitar 200 mdpl pada kemiringan topografi yang bervariasi mulai dari curam, agak curam sampai datar. Sering ditemukan pada batang pohon mati yang kering, dibalik rantingranting dan di pinggir hutan bekas tebangan. Secara periodik kadal jenis ini pada musim tertentu akan selalu menghabiskan waktu didalam hutan dan keluar hutan hanya sekedar berjemur pada sinar matahari. Makanan dari jenis kadal ini adalah serangga, jentik-jentik nyamuk, telur semut dan mikroorganisme lainnya yang lebih kecil dari tubuh jenis kadal ini (Kurniati 2001).

\section{Emoia sp.}

Panjang tubuh mulai dari moncong sampai pada ujung ekor (SVL) $8 \mathrm{~cm}$, panjang mulai dari tibia sampai pada ujung ekor $5 \mathrm{~cm}$, panjang kepala sampai leher $1,5 \mathrm{~cm}$, lebar kepala $1 \mathrm{~cm}$, letak mata horizontal, bentuk mata oval, mempunyai empat kaki, setiap kaki mempunyai jari-jari, tungkai kaki depan mempunyai jari empat dan tungkai kaki belakang mempunyai 5 ruas jari, warna kulit hitam mengkilat bintik-bintik putih pada bagian samping perut, tekstur tubuh licin.

Kadal ini banyak dijumpai pada lantai hutan primer dan hutan sekunder, kelembaban sedang suhu berkisar $29^{\circ} \mathrm{C}$. Kadal jenis ini termasuk kadal jenis semi arboreal, sering memanjat namun sebagian besar hidupnya di tanah (teresterial) dan dapat dijumpai pada ketinggian 210 mdpl. Selain dapat ditemukan di dalam hutan, disepanjang sungai, anak sungai dan rawa yang rumputnya tebal kadal jenis ini dapat dijumpai. Makanan kadal ini berupa serangga kecil dan jentik-jentik nyamuk serta mikroorganisme yang berukuran sangat kecil (Kurniati 2001).

\section{Emoia caeruleocouda (Des, 1892).}

Panjang tubuh mulai dari moncong sampai pada ujung ekor (SVL) 9,5 cm, bentuk kepala loncong, letak pupil horizontal, bentuk pupil oval, mempunyai empat kaki pada setiap kakinya terdapat lima ruas jari-jari yang sempurna, tungkai kaki depan dan belakang masing-masing mempunyai ruas jari-jari 5 , warna tubuh hitam bergaris putih mulai dari moncong sampai pada tibia/ekor, ekor berwarna biru namun pada fase tertentu atau usia tertentu warna ekor akan berubah menjadi keabu-abuan, tekstur badan licin dan mengkilat. Kadal jenis ini banyak dijumpai pada areal terbuka dan atau hutan yang vegetasinya rendah, semaksemak dan batu-batuan merupakan habitat yang disenangi karena pada saat tertentu lubang atau cela-cela batu bisa dijadikan tempat berlindung ketika terdapat predator dan sebagai tempat berteduh ketika cuaca panas. Kadal ini dapat 
dijumpai pada ketinggian 10-30 mdpl dengan suhu rata-rata $30{ }^{\circ} \mathrm{C}$. Emoia caeruleocauda merupakan jenis kadal yang hidupnya dipermukaan tanah (teresterial) dan tempat bekas bakaran api. Jenis pakan jenis kadal ini meliputi serangga yang berukuran kecil, jentikjentik nyamuk, kupu-kupu dan mikroorganisme lain yang ukuran tubuh lebih kecil dari pada tubuhnya (Kurniati 2001).

\section{Leprolepis smaragdina (Lesson, 1830).}

Panjang tubuh mulai dari moncong sampai ujung ekor (SVL) $21 \mathrm{~cm}$, panjang ekor $13 \mathrm{~cm}$, panjang kepala $3 \mathrm{~cm}$, lebar kepala 1,5 cm, bentuk kepala lonjong dan meruncing, letak pupil horizontal, bentuk pupil oval, mempunyai empat tuas kaki pada setiap tuas kakinya mempunyai lima ruas jari, pada kaki depan terdapat lima jari dan pada tuas kaki belakang terdapat lima jari, warna tubuh bagian kepala sampai leher warna hijau, bagian perut sampai ujung ekor warna abu-abu, tubuhnya licin dan mengkilap.

Kadal jenis ini berada pada hutan yang bervegetasi rendah, hidup berada di pohon-pohon (arboreral). Aktifitas lebih banyak dihabiskan di atas pohon. Kadal jenis ini dapat djumpai pada semua jenis pohon yang mempunyai daun yang lebat. Biasanya jenis kadal ini dijumpai pada ketinggian 10-30 mdpl dengan suhu ratarata 29-30 ${ }^{\circ} \mathrm{C}$. Sering di jumpai pada pohon yang ribun. Terkadang juga dijumpai pada lantai hutan bekas tebangan atau lahan pertanian/perkenunan.

Jenis pakan kadal ini adalah serangga yang berukuran kecil, jentik-jentik nyamuk, telur semut dan mikrooraganisme lain seperti kupu-kupu, semut dan kepompong (Kurniati 2001).

\section{Jumlah Individu dan Keanekaragaman Jenis}

Gambaran secara rinci tentang jenis dan jumlah individu masing-masing jenis kadal yang teridentifikasi di kawasan Taman Wisata Alam Gunung Meja berdasarkan frekuensi pengamatan adalah sebagai berikut:

1. Frekuensi I

Pada frekuensi pengamatan I teridentifikasi jenis Sphenomorphus sp. sebanyak 6 individu, Carlia fusca (Dumeril \& Bibron, 1836) sebanyak 4 individu, Sphenomorphus variegatus (Peters, 1867) sebanyak 3 individu, emoia sp. sebanyak 2 individu, Emoia caeruleocauda (Des, 1892) sebanyak 3 individu dan leprolepis smaragdia (Lesson, 1830) sebanyak 5 individu.

2. Frekuensi II

Pada frekuensi pengamatan kedua diidentifikasi jenis Sphenomorphus sp. sebanyak 5 individu, Carlia fusca (Dumeril \&Bibron, 1836 ) sebanyak 3 individu, Sphenomorphus variegatus (Peters, 1867) sebanyak 2 individu, emoia sp. sebanyak 3 individu, Emoia caeruleocouda (Des, 1892) sebanyak 3 individu, Laprolepis smaragdia (Lesson, 1830) sebanyak 2 individu.

\section{Frekuensi III}

Pada frekuensi pengamatan ketiga teridentifikasi jenis Spernomorphus sp. sebanyak 4 individu, Carlia fusca (Dumeril \&Bibron, 1836) sebanyak 6 individu, Sphenomorphus variegatus (Peters, 1867) sebanyak 7 individu, Emoia sp. sebanyak 2 individu, Emoia caeruleocouda (Des, 1892) sebanyak 4 individu, Laprolepis smaragdia (Lesson, 1830) sebanyak 4 individu. 
4. Frekuensi IV

Pada frekuensi pengamatan keempat teridentifikasi jenis Sphenomorphus sp. sebanyak 9 individu, Carlia fusca (Dumeril \&Bibron, 1836) sebanyak 5 individu, Sphenomorphus variegatus (Peters, 1867) sebanyak 9 individu, Emoia sp. sebanyak 3 individu, Emoia caeruleocouda (Des, 1892) sebanyak 2 individu, Laprolepis smaragdia (Lesson, 1830) sebanyak 4 individu.

\section{Frekuensi V}

Frekuensi pengamatan kelima teridentifikasi jenis Sphenomorphus sp. sebanyak 6 individu, Carlia fusca (Dumeril \&Bibron, 1839) sebanyak 6 individu, Sphenomorphus variegatus (Peters, 1867) sebanyak 3 individu, Emoia sp. sebanyak 6 individu, Emoia caeruleocouda (Dess, 1892) sebanyak 2 individu, Laprolepis smaragdnia (Lesson, 1830) sebanyak 7 individu. Rekapitulasi jenis dan jumlah individu masing-masing jenis kadal yang teridentifikasi di kawasan Taman Wisata Alam Gunung Meja dapat dilihat pada tabel berikut

Tabel 1. Frekuensi pengamatan dan jumlah penjumpaan individu

\begin{tabular}{llllllll}
\hline No & Nama jenis & F1 & F2 & F3 & F4 & F5 & \multirow{2}{*}{$(\Sigma)$} \\
\cline { 3 - 6 } & & ni & ni & ni & ni & ni & individu \\
\hline 1 & Sphenomophus sp. & 6 & 5 & 4 & 9 & 6 & 30 \\
2 & Sphenomophus variegatus (Peters, 1867) & 3 & 2 & 7 & 9 & 3 & 27 \\
3 & Carlia fusca (Dumeril \&Bibron, 1836) & 4 & 3 & 6 & 5 & 6 & 24 \\
4 & Laprolepis smaragdina (Lesson, 1830) & 5 & 2 & 4 & 4 & 7 & 22 \\
5 & Emoia sp. & 2 & 3 & 2 & 3 & 6 & 16 \\
6 & Emoia caeruleocouda (Dess, 1892) & 3 & 3 & 4 & 2 & 2 & 14 \\
& $\quad$ Jumlah & & & & & & 133 \\
\hline
\end{tabular}

Tabel 2. Jumlah jenis keragaman dan kemeratanan individu

\begin{tabular}{llccc}
\hline No. & \multicolumn{1}{c}{ Jenis } & $\begin{array}{c}\text { Individu } \\
\text { (ni) }\end{array}$ & H & E \\
\hline 1. & Sphenomophus sp. & 30 & 0,14 & 0,19 \\
2. & Sphenomophus variegatus (Peters, 1867) & 27 & 0,31 & 0,17 \\
3. & Carlia fusca (Dumeril \&Bibron, 1836) & 24 & 0,32 & 0,18 \\
4. & Laprolepis smaragdina (Lesson, 1830) & 22 & 0,25 & 0,14 \\
5. & Emoia sp. & 16 & 0,24 & 0,13 \\
6. & Emoia caeruleocouda (Des, 1892) & 14 & 0,30 & 0,17 \\
& Jumlah & 133 & 1,76 & 0,98 \\
\hline
\end{tabular}

Hasil analisis pengamatan menunjukkan bahwa dari 6 jenis kadal yang ditemukan, jenis dengan jumlah individu terbanyak adalah
Sphenomrophus sp. dan terendah adalah Emoia caeruleocouda (Dess, 1892). Kondisi ini menggambarkan tingkat adaptasi yang berbeda dari kedua jenis 
kadal ini dengan konsekwensi bahwa jenis dengan jumlah individu banyak menunjukkan tingkat adaptasi yang sangat baik dari individunya terhadap habitat, demikian sebaliknya.

Dari hasil analisis menunjukkan bahwa indeks keanekaragaman jenis kadal di kawasan Taman Wisata Alam Gunung Meja berkisar adalah 1,76. Kriteria indeks keanekaragaman atau derajat keanekaragaman jenis menurut Shanon dan Wiener (1949), Odum (1993) dalam Sinery et al. (2012) adalah bahwa keanekaragaman jenis tinggi bila indeks keanekaragaman jenis lebih dari tiga $(\mathrm{H} \geq$ 3), sedang bila keanekaragaman jenis berada antara satu sampai tiga $(1<\mathrm{H}<3)$ dan rendah bila keanekaragaman jenis kurang dari satu $(\mathrm{H}<1)$. Berdasarkan kriteria tersebut, maka keanekaragaman jenis kadal famili Scincidae pada hutan ini adalah sedang. Nilai tersebut dapat pula dikelompokkan dalam kriteria cukup tinggi atau mendekati nilai kestabilan/kemantapan yaitu 3,39 (Kungse, 1995 dalam Sinery et al. 2012) atau kategori cukup tinggi 3,50 (Soerianegara, 1996 dalam Sinery et al. 2012).

Tingkat kemerataan jenis menunjukkan bahwa indeks kemerataan jenis kadal adalah 0,98. Menurut Krebs (1978) dalam Odum (1993) dalam sinery et al. 2012) bahwa nilai kemerataan tinggi bila $\mathrm{E}=>0,6$, kemerataan sedang $\mathrm{E}=0,4$ $<\mathrm{E} \leq 0,6$ dan kemerataan rendah bila $\mathrm{E}=$ $0<\mathrm{E} \leq 0,4$. Berdasarkan kriteria tersebut, maka indeks kemerataan jenis kadal di Taman Wisata Gunung Meja adalah tinggi. Kisaran nilai kemerataan jenis menurut Krebs (1989) dalam Soegianto (1994) dalam sinery et al. 2012) yaitu berkisar antara 0 sampai 1. Menurut Santosa (1995) dalam Sinery et a. (2012), bahwa indeks kemerataan jenis menunjukkan ukuran proporsi individu pada setiap spesies pada suatu komunitas. Bila setiap jenis memiliki jumlah individu yang sama maka komunitas tersebut memiliki nilai indeks kemerataan jenis maksimum.

\section{DAFTAR PUSTAKA}

Hamidy A dan Mulyadi. 2007. Herpetofauna di Pulau Waigeo. Museum Zoologicum Bogoriense Bidang Zoologi, Pusat Penelitian Biologi Lembaga Ilmu Pengetahuan Indonesia.

http://biologi.lipi.go.id/zoologi/image s/file download/herpet/laporan/herpet ofauna waigeo papua.pdf.

Kurniati H. 2001. Analisis ekologi relung intraspesifik kadal sphenomorphus variegatus di tinjau dari mangsa alaminya. Bidang Zoologi, PUSLIT. BiologiLIPI/jurnal28:818Cibinong.http://jurn al.zoo.puslitbiologilipi/html.

Mack, Andrew L and Leeanne E. Alonso (eds.). 2000. A biological assessment of the Wapoga River area of Northwestern Irian Jaya, Indonesia. RAP Bulletin of Biological Assessment 14, Conservation International, Washington, DC.

Muller K. 2005. Keragaman hayati tanah papua/biodiversity of Papua island.

Sinery AS. 2006. Jenis kuskus di Taman Wisata Gunung Meja Kabupaten Manokwari, Irian Jaya Barat. Biodiversitas, 7 (2): 175-180.

Sinery A, Boer C, Farida W. 2012. The population condition and food availability of cuscus in Arfak Mountains Nature Reserve, West Papua. Biodiversitas, 13 (2): 86-91. 
Werimon IA. 2006. Keanekaragaman jenis herpetofauna di sekitar sungai Mamdifu kampung Urbin Asopen,

pada pulau Waigeo. Skripsi jurusan biologi UNIPA Manokwari (tidak d terbitkan). 